\title{
Evaluation of Self-reported Patient Experiences: Insights from Digital Patient Communities in Psoriatic Arthritis
}

\author{
Prashanth Sunkureddi, Stephen Doogan, John Heid, Samir Benosman, Alexis Ogdie, \\ Layne Martin, and Jacqueline B. Palmer
}

ABSTRACT. Objective. To evaluate the types of experiences and treatment access challenges of patients with psoriatic arthritis (PsA) using self-reported online narratives.

Methods. English-language patient narratives reported between January 2010 and May 2016 were collected from 31 online sources (general health social networking sites, disease-focused patient forums, treatment reviews, general health forums, mainstream social media sites) for analysis of functional impairment and 40 online sources for assessment of barriers to treatment. Using natural language processing and manual curation, patient-reported experiences were categorized into 6 high-level concepts of functional impairment [social, physical, emotional, cognitive, role activity (SPEC-R), and general] and 6 categories to determine barriers to treatment access (coverage ineligibility, out-of-pocket cost, issues with assistance programs, clinical ineligibility, formulary placement/sequence, doctor guidance). The SPEC-R categorization was also applied to 3 validated PsA patient-reported outcome (PRO) instruments to evaluate their capacity to collect lower-level subconcepts extracted from patient narratives.

Results. Of 15,390 narratives collected from 3139 patients with PsA for exploratory analysis, physical concepts were the most common $(81.5 \%)$, followed by emotional $(50.7 \%)$, cognitive $(20.0 \%)$, role activity $(8.1 \%)$, and social (5.6\%) concepts. Cognitive impairments and disease burden on family and parenting were not recorded by PsA PRO instruments. The most commonly cited barriers to treatment were coverage ineligibility (51.6\%) and high out-of-pocket expenses $(31.7 \%)$.

Conclusion. Patients often discussed physical and emotional implications of PsA in online platforms; some commonly used PRO instruments in PsA may not identify cognitive issues or parenting/family burden. Nearly one-third of patients with PsA reported access barriers to treatment. (First Release February 15 2018; J Rheumatol 2018;45:638-47; doi:10.3899/jrheum.170500)

\section{Key Indexing Terms: \\ PSORIATIC ARTHRITIS PATIENT-REPORTED OUTCOME MEASURES \\ PATIENT INSIGHTS}

\footnotetext{
From The University of Texas Medical Branch, Galveston, Texas; Real Life Sciences Inc., New York; CreakyJoints, Global Healthy Living Foundation, Upper Nyack, New York; Perelman School of Medicine at the University of Pennsylvania, Philadelphia, Pennsylvania; Novartis Pharmaceuticals Corporation, East Hanover, New Jersey, USA; Kinapse Ltd., London, UK. Sponsored by Novartis Pharmaceuticals Corporation, East Hanover, New Jersey, USA. The design and conduct of this research was a collaborative effort between Kinapse and Novartis, and financial support for this research was provided by Novartis. Novartis participated in the interpretation of data, and review and approval of the manuscript. Support for third-party writing assistance for this manuscript, furnished by Eric Deutsch, PhD, of Health Interactions Inc., was provided by Novartis Pharmaceuticals Corporation.

P. Sunkureddi, MD, The University of Texas Medical Branch; S. Doogan, BA, Real Life Sciences Inc.; J. Heid, BA, Kinapse Ltd.; S. Benosman, DVM, PhD, Kinapse Ltd.; A. Ogdie, MD, MSCE, Perelman School of Medicine at the University of Pennsylvania; L. Martin, RN, CreakyJoints, Global Healthy Living Foundation; J.B. Palmer, PharmD, Novartis Pharmaceuticals Corporation.

Address correspondence to Dr. P. Sunkureddi, 2060 Space Park Drive, Suite 208, Nassau Bay, Texas 77058, USA.

E-mail:DrSunkureddi@clearlakerheumatology.com

Full Release Article. For details see Reprints and Permissions at jrheum.org Accepted for publication November 7, 2017.
}

Psoriasis is an inflammatory autoimmune disease of the skin that affects $0.5 \%$ to $3.5 \%$ of the global population ${ }^{1}$. About $30 \%$ of patients with psoriasis will develop psoriatic arthritis (PsA), a chronic, inflammatory disease affecting the musculoskeletal system ${ }^{2,3}$. PsA may present with $\geq 1$ clinical subtype, including peripheral joint inflammation, enthesitis, dactylitis, axial spondylitis, and varying severity of nail and skin changes; the heterogeneous aspect of this disease makes diagnosis and treatment challenging ${ }^{4,5}$. Some patients with PsA may experience destruction of the joints, and functional and psychosocial impairments are common ${ }^{6,7,8}$. Additionally, PsA is associated with an increased prevalence of comorbidities such as metabolic and cardiovascular disease, further complicating management of the disease ${ }^{9}$.

One way to better measure the burden of disease is to observe how patients describe their disease in social settings. Patients actively participate in online communities to obtain support and empathy through peer-to-peer connections. Online platforms go beyond the typical social networks such

Personal non-commercial use only. The Journal of Rheumatology Copyright (c) 2018. All rights reserved. 
as Facebook or Twitter; online communities such as PatientsLikeMe, TalkPsoriasis [hosted by the National Psoriasis Foundation (NPF)], or Living With PsA are examples of social media outlets available for patients with PsA ${ }^{10,11,12}$. Patients in these communities discuss symptoms, describe their experiences with accessing and using different treatments, and provide links to research articles on psoriasis and PsA. These online communities offer a plethora of information on firsthand experiences and how patients, family members, and caregivers deal with their disease burden.

Although clinical and laboratory variables are used to measure disease activity and severity, patient-reported outcome (PRO) measures are equally important and represent a critical firsthand account of the patient's perception of well-being and response to treatment ${ }^{13}$. Some of the PRO instruments used in PsA clinical trials were initially created for other diseases ${ }^{14,15,16,17}$; other generic PRO instruments are also used in PsA trials with the goal of characterizing overall population health, including the Medical Outcomes Study 36-Item Short Form Survey (SF-36) ${ }^{18}$. PRO instruments such as Psoriatic Arthritis Quality of Life questionnaire (PsAQoL), the Psoriasis Symptom Inventory, and the Psoriatic Arthritis Impact of Disease questionnaire (PsAID) have all made strides to incorporate patient feedback in the disease-specific measurement of PRO in PsA $19,20,21,22$.

PRO instruments broadly measure patients' experiences with PsA in clinical trials and other studies, are heterogeneous in design, and may not be routinely or consistently used in clinical practice ${ }^{23}$. Real-world studies that exquisitely examine the well-being of patients with PsA as well as the psychological and emotional aspects of disease are scarce, and available studies in PsA do not generally record the daily struggles and obstacles that patients experience ${ }^{24,25}$. The objectives of our exploratory study were to better understand the effect of PsA on patients' lives through the experiences that patients self-report online, to map concepts discussed by patients to those identified by commonly used PRO instruments in PsA, and to characterize the challenges and barriers to treatment access reported by patients.

\section{MATERIALS AND METHODS}

Patients and data sources. From an aggregate of thousands of online healthcare sources, English-language patient narratives reported between January 2010 and May 2016 were collected from 31 online sources for analysis of functional impairment and from 40 online sources for assessment of barriers to treatment in patients with PsA (Appendix 1). Data sources included general health social networks, disease-focused and general health forums, treatment review forums, and mainstream social media networks. The final sources were ultimately chosen based on whether participants reported having PsA and $\geq 1$ symptom or functional impairment. Preexisting and unsolicited spontaneous patient and caregiver narratives and/or conversations relating to real-world experiences with PsA and associated treatments were obtained from publicly available, patient-led social media reports. No password-protected sites were accessed, nor were any personally identifiable patient data used in the generation of the study results; no direct identifiers were used/extracted, and any quasi-identifiers were transformed into aggregate forms. No patient recruitment was conducted. Thus, approval from institutional review boards was not mandatory.

To reduce potential duplication of patients who reported experiences as users or members across multiple online platforms, statistical models were used to compare factors across reports (e.g., username, time stamps of reports, concepts contained within the reports). If these factors appeared highly similar across users, the profiles were tagged and flagged for review through a manual curation process to ensure that all attempts were made to remove duplicates.

Data qualification and categorization. Using a natural language processing platform (RLytics; Real Life Sciences Inc.) and manual expert curation, functional impairments and symptoms related to PsA were extracted from patient narratives and classified into 6 high-level concepts based on analysis of commonly occurring concepts within existing PRO instruments: social, physical, emotional, cognitive, role activity (SPEC-R), and general (consisting of nonspecific narratives, such as "feeling unwell"). The SPEC-R framework was built on curated taxonomies that are used to codify and structure key elements of interest from unstructured patient narratives. For example, a patient may post the following experience to social media: "I was diagnosed with PsA last year and have been in so much pain." From this statement, high-level concepts can be extracted [e.g., reporter (patient), medical condition (PsA), medical condition/symptom (pain)]. This framework allowed for unguided patient commentary to be translated into structured patient data. These broad categories provided a starting point for organization of the data from patient narratives, with additional levels of detail added through more granular subconcept groupings (Table 1). All subconcepts were derived from categorizations of symptomatology and functions from existing medical dictionaries and taxonomies, such as those established by the Medical Dictionary for Regulatory Activities or The International Classification of Functioning, Disability and Health (ICF) developed by the World Health Organization. A similar natural language processing approach was used to identify whether these medical conditions were reported as hypothetical (i.e., reported but not experienced) or as a "true experience" from someone who has actually had the condition (e.g., "I/me," "my son/daughter," "my husband/wife").

Mapping concepts identified to PRO instruments. SPEC-R categorization was applied to 3 commonly used PRO instruments validated in clinical studies of patients with PsA: the SF-36, PsAQoL, and PsAID; 39 subconcepts were identified across 68 questions from the PRO instruments. The SF-36 is a generic measure of health-related quality of life originally developed for use in the general population but has since been validated in patients with $\mathrm{PsA}^{18,26,27}$, and is widely used in clinical trials in $\mathrm{PsA}^{28-34}$. The PsAQoL is a 20 -item questionnaire developed largely from unstructured, qualitative interviews with patients with PsA and evaluates aspects of disease including fatigue, mood, and social participation ${ }^{19}$. Lastly, the PsAID was developed for use in clinical trials (as the 9-item PsAID-9) and in clinical practice (the PsAID-12), based on input from patients across 13 countries $^{21}$. The PsAID measures the general effect of disease on life and is the only tool that measures sleep disturbance.

Questions from existing PRO instruments were classified into the same broad concepts and lower-level subconcepts. For example, 1 item on the PsAID instructs the user to "[c]ircle the number that best describes the pain you felt due to your psoriatic arthritis during the last week"21; this would be categorized under "pain" within the physical concept. The 3 PsA-specific PRO instruments were then mapped to key concepts and subconcepts extracted from patient narratives to evaluate the capability of each instrument to identify frequently reported patient experiences from online sources.

Assessment of treatment barriers. Using a process similar to that described above, patient-reported barriers to treatment access were identified from patient narratives of those who reported experience with biologics and/or small-molecule agents, and organized into 6 high-level categories: coverage ineligibility, out-of-pocket cost, issues with assistance programs, clinical ineligibility, formulary placement/sequence, and doctor (i.e., prescriber) guidance.

Personal non-commercial use only. The Journal of Rheumatology Copyright $\subset$ 2018. All rights reserved. 
Table 1. Overview of high-level concept categories and lower-level subconcepts.

\begin{tabular}{|c|c|c|}
\hline SPEC-R Category & Lower-level Concepts & Description \\
\hline \multirow[t]{4}{*}{ Social } & Lack of independence & Help needed to groom oneself, run errands, bathe \\
\hline & Relationships (family) & Pressure on family members, strained relationships with children \\
\hline & Social life/activities & Going out with friends, staying in contact with friends \\
\hline & Relationships (friends) & Talking with friends about PsA, maintaining friendships \\
\hline \multirow[t]{7}{*}{ Physical } & Pain & General pain, headaches, muscle pain, musculoskeletal pain \\
\hline & Dermatologic & Rashes, itching, dryness \\
\hline & Movement/physical activity & Difficulty walking, gait disturbance, bedridden, difficulty driving \\
\hline & Gastrointestinal & Bloating, flatulence, nausea, vomiting \\
\hline & Ocular & Blurred vision, loss of vision, visual disturbances \\
\hline & Respiratory & Difficulty breathing, irregular breathing, anaphylaxis \\
\hline & Sleep & Sleep disturbance, insomnia, abnormal sleep patterns \\
\hline \multirow{3}{*}{ Emotional } & Sadness & Tearful, crying, feeling empty \\
\hline & Difficulty coping & Coming to terms, concern about the future \\
\hline & Suicidal and self-injurious behavior & Suicidal ideation, suicide attempts \\
\hline \multirow[t]{6}{*}{ Cognitive } & Mental impairment & Trouble thinking, difficulty thinking, cognitive difficulties \\
\hline & Impulsivity & $\begin{array}{l}\text { Nail biting, impulse control, general loss of control, alcohol dependence, opiate } \\
\text { addiction, withdrawal syndrome }\end{array}$ \\
\hline & Balance/coordination & $\begin{array}{l}\text { Poor balance (from mental fatigue and/or dizziness), unsteadiness, fainting, blackout, } \\
\text { passing out }\end{array}$ \\
\hline & Memory & Forgetful, bad memory, short-term memory loss \\
\hline & Speech & Slurring, babbling, stuttering, difficulty speaking \\
\hline & Concentration & $\begin{array}{l}\text { Short attention span, easily distracted, daydreaming, distractibility, difficulty } \\
\text { concentrating }\end{array}$ \\
\hline
\end{tabular}

SPEC-R: social, physical, emotional, cognitive, role activity; PsA: psoriatic arthritis.

\section{RESULTS}

Data source and patient population. A total of 15,390 narratives from 3139 patients with PsA were identified for this exploratory analysis. Of these, $56.2 \%$ were collected from general health social networking sites, $22.0 \%$ from disease-focused patient forums, $11.9 \%$ from treatment reviews, $9.9 \%$ from general health forums, and $0.1 \%$ from mainstream social media sites.

Data on age and sex were available for 762 patients with PsA; the median age was 44.0 years, and 516 patients $(67.7 \%)$ were female. Of the 679 patients with geographic information available, most patients $(81.0 \%)$ were from North America, with the remainder coming from Europe $(10.8 \%)$, Oceania $(4.7 \%)$, Asia $(2.7 \%)$, Central America $(0.4 \%)$, and Africa $(0.4 \%)$.

Social, physical, emotional, cognitive, and role activity analysis of patient narratives. Of the 15,390 narratives collected from 3139 patients with PsA, 81.5\% of patients $(n=2557)$ reported concerns correlated to the physical concept, $50.7 \%(n=1592)$ to emotional, $20.0 \%(n=629)$ to cognitive, $8.1 \%(n=254)$ to role activity, and $5.6 \%(n=176)$ to social. In addition, $66.8 \%(\mathrm{n}=2097)$ reported general concepts (e.g., "feeling unwell"; Figure 1). Most of the issues patients with PsA reported online comprised physical concepts, with about 4 of 5 patients (2557/3139) reporting $\geq 1$ issue related to the physical concepts, including pain (1677/2557, 65.6\%), dermatologic issues $(657 / 2557,25.7 \%)$, and physical weakness $(555 / 2557,21.7 \%$; Figure 2$)$.

Emotional concepts were reported by just over one-half of patients $(1592 / 3139 ; 50.7 \%)$ and were most commonly associated with concerns related to anxiety (958/1592, $60.2 \%$ ) and depression (455/1592, 28.6\%; Figure 2). Emotional issues were often linked to concepts in other categories, such as pain or itching. For example, one patient 


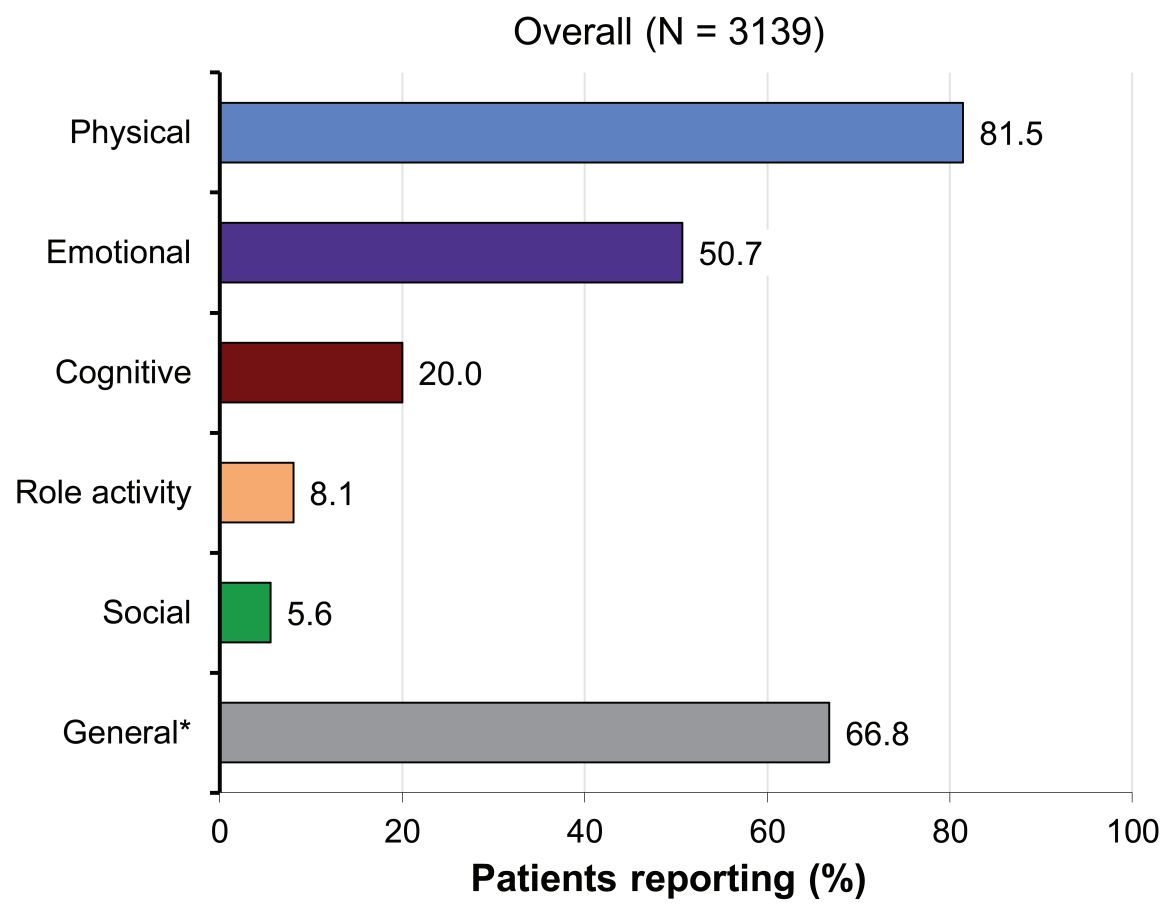

Figure 1. Online patient reports across all categories of the SPEC-R analysis. *General concepts consisted of nonspecific narratives (e.g., "feeling unwell"). SPEC-R: social, physical, emotional, cognitive, and role activity.

reported, “... but this eye problem scares me more, and I can't imagine coping with it for years," while another expressed frustration with the disease: "[e]specially when you're dealing with so much pain and no easy solutions, the anger and negativity will just keep snowballing and drag you further down." Overall, 20.0\% of patients (629/3139) reported concerns related to cognitive concepts, with impulsivity $(159 / 629,25.3 \%)$ and balance/coordination issues from mental fatigue and/or dizziness $(78 / 629,12.4 \%)$ as the most common concerns within this category (Figure 2).

Role activity concepts were present in experiences reported by $8.1 \%$ (254/3139) of patients with PsA. Among patients who reported how PsA affected their daily activities, more than one-half of patients $(141 / 254,55.5 \%)$ were concerned about how PsA affected their work/school performance, and $17.3 \%$ of patients (44/254) expressed concern about the effect of PsA on parenting (e.g., " [j] ust worried as have 5 little ones to take care of, it is already affecting my ability to look after them"; Figure 2). As with role activity concepts, social concepts were rarely discussed and were reported by only $5.6 \%$ of patients (176/3139); however, about one-half of patients who reported social issues discussed family burden (88/176; eg, “...I was finally forced to learn about it so that means talking to my family about it"), and about one-quarter of reported social impairments involved relationship issues with a partner or spouse (47/176; Figure 2).

Analysis of PsA-specific PRO instruments. Some of the common social (work/school performance, partner/spouse relationships, and group social activities), physical (pain, fatigue/weakness), and emotional (anxiety, depression/ sadness) concepts reported online by patients were effectively covered by $\geq 2$ of the PRO instruments (Table 2). However, other concepts, such as the effect of dermatologic issues, anger/frustration, family burden, parenting, and cognitive impairments, were either not covered or were covered by only 1 of the PRO instruments.

Although the SF-36 covered many of the patient-relevant issues such as social activities, pain, fatigue, anxiety, depression, and work/school-related activities, the SF-36 was not equipped to evaluate any cognitive impairments. The PsAQoL included items to evaluate issues such as fatigue/ energy, depression, and anger, which identified many of the physical and emotional concepts discussed in this study; however, pain, dermatologic issues, and anxiety were missing. Further, the PsAQoL did not cover any of the concepts related to the cognitive or role activity categories.

The PsAID covered many of the same common concepts and subconcepts reported online in our study as the PsAQoL and the SF-36, but the PsAID also assessed dermatologic issues. However, as with the SF-36 and the PsAQoL, the PsAID did not adequately cover reports of cognitive or role activity impairments.

Patient-reported barriers to treatment access. Of 1485 patients with PsA who had experience with biologics and/or small-molecule agents, $27.0 \%$ (401/1485) reported barriers

Personal non-commercial use only. The Journal of Rheumatology Copyright @ 2018 . All rights reserved. 


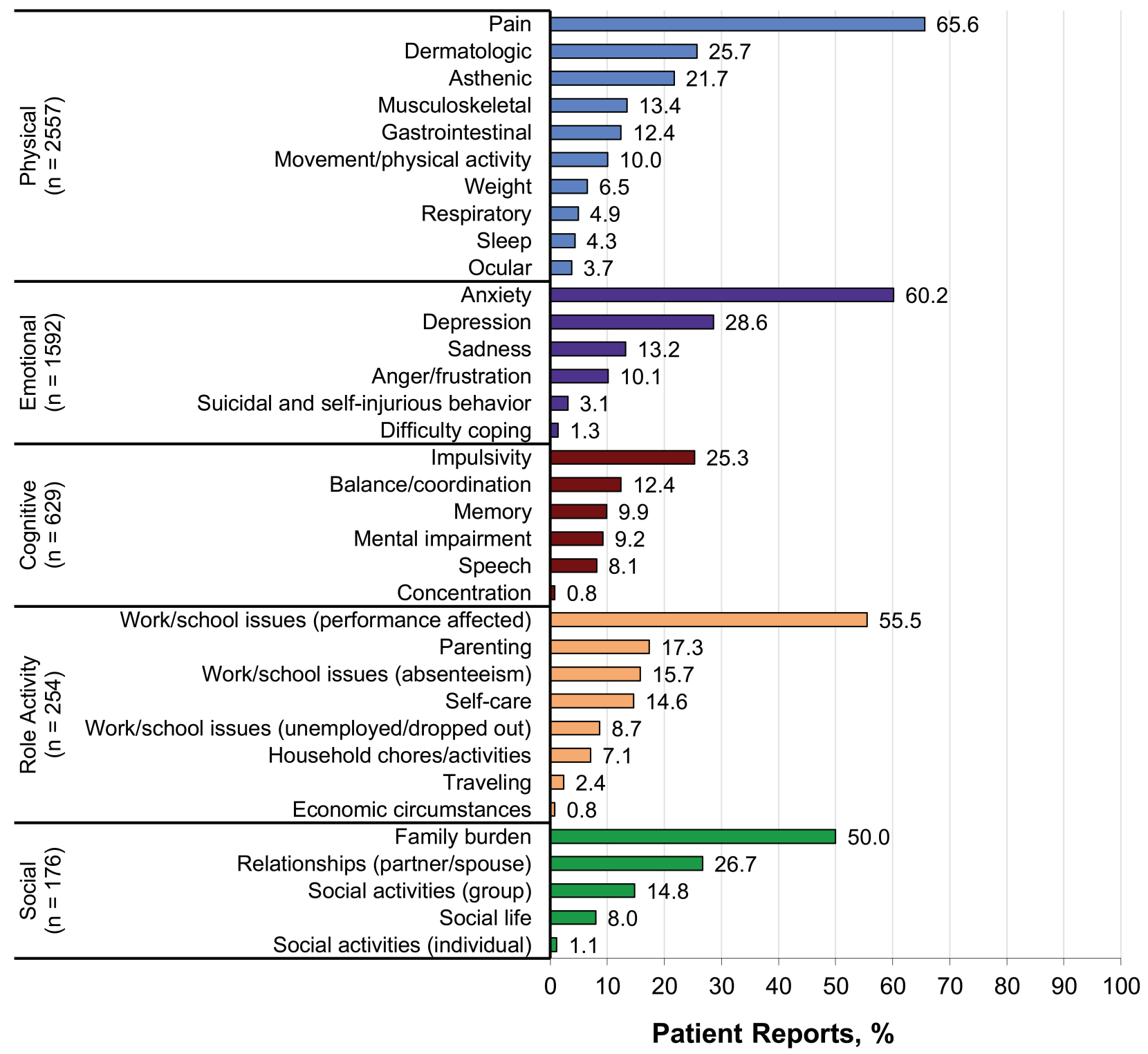

Figure 2. Patient narratives for each lower-level concept of the SPEC-R analysis. Percentages represent the proportion of narratives within each highlevel SPEC-R category. SPEC-R: social, physical, emotional, cognitive, and role activity.

to treatment access. Among the patients with available demographics, the majority were female $(58 \%)$, with a median age of 40 years. Coverage ineligibility (207/401, $51.6 \%)$ and out-of-pocket costs $(127 / 401,31.7 \%)$ were the most commonly reported barriers to treatment access (Figure 3A). Reasons for ineligibility were mostly unspecified (157/207, 75.8\%; e.g., insurance provider denied treatment until confirmation of PsA diagnosis); however, 19.3\% (40/207) reported delayed access, $11.1 \%$ (23/207) reported reduced coverage, and $6.3 \%$ (13/207) reported discontinued coverage (Figure 3B). For patients who cited out-of-pocket expenses as barriers to treatment access, out-of-pocket affordability (e.g., discontinuing treatments because of cost) and copay/insurance affordability (e.g., unable to afford copay- ments for expensive biologics) were the most common reasons reported $(101 / 127,79.5 \%$; and 35/127, 27.6\%, respectively).

\section{DISCUSSION}

Our exploratory study aggregated and analyzed thousands of narratives of patients with PsA self-reported online to determine which concepts were most important to patients and to evaluate whether these concepts were adequately identified by commonly used PRO instruments in PsA studies.

A previous systematic literature review of qualitative publications linking the effect of PsA on quality of life found that impairments in the ability to work/volunteer and social 
Table 2. Summary of PRO instrument coverage of key social, physical, emotional, cognitive, and role activity concepts.

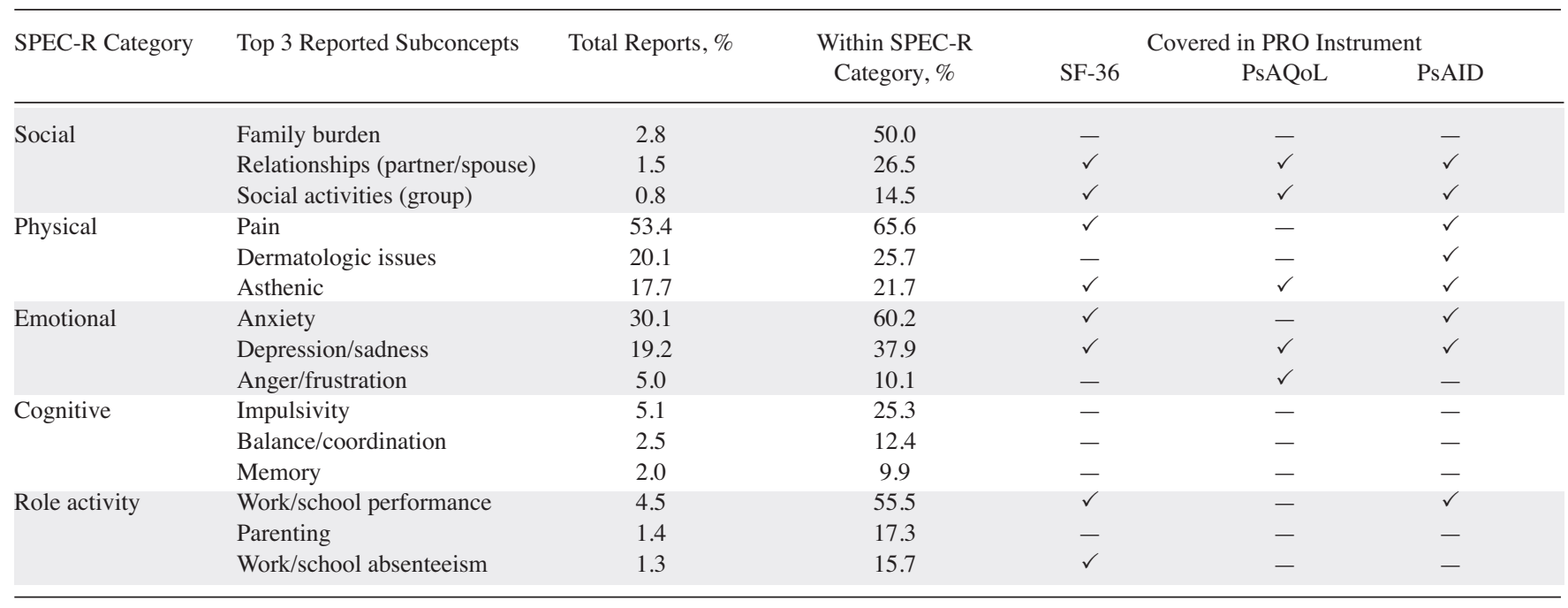

PRO: patient-reported outcome; SPEC-R: social, physical, emotional, cognitive, role activity; SF-36: Medical Outcomes Study Short Form-36 questionnaire; PsAQoL: Psoriatic Arthritis Quality of Life questionnaire; PsAID: Psoriatic Arthritis Impact of Disease questionnaire.

participation were most commonly cited, with impairments in "activities and participation" as the most represented ICF component $(42.6 \%)^{24}$. In our current study, physical concepts were the most common issues reported by patients with PsA, with pain and dermatologic concerns being cited the most often. One-half of patients reported emotional issues, largely driven by anxiety and depression, while one-fifth of patients reported cognitive issues, such as impulsivity and balance/ coordination. In patients with PsA, online reporting on social and role activities was less frequent than the other categories. Although emotional and cognitive impairments may be more directly linked to disease symptoms or consequences of intensive treatment regimens than social or role activity concepts, it is also possible that patients may not be fully aware that they are isolating themselves because of their disease until they are asked directly about these concepts. The patients who did discuss role activity and social concepts focused on work/school performance and issues surrounding family burden. The low reporting of social or role activity concepts is an interesting finding, as "work and/or leisure activities" was prioritized as the fourth most important domain by 139 patients with PsA in development of the PsAID $^{21}$. Perhaps this lack of prioritization of social or role activity concepts is because of physical, emotional, and cognitive concepts being constant in a patient's life, whereas social and role activity concepts may not be (e.g., workday lasts about $8 \mathrm{~h}$ per day, but pain is continuous). Additionally, patients could be retired or placed out of work because of the disease, thus mitigating the need to mention work activity/ performance or other such topics in online communities. The importance of pain, fatigue, and dermatologic issues reported in our study is consistent with the recently updated PsA core domain set developed by the Group for Research and
Assessment of Psoriasis and Psoriatic Arthritis and the Outcome Measures in Rheumatology (OMERACT) working group for use in randomized clinical trials and observational studies, which was based on a rigorous process that included a systematic literature review, patient focus groups, surveys of patients and physicians, face-to-face meetings with physicians and patients, and presentation of domains at the OMERACT conference in $2016^{35}$.

Overall, PRO instruments used to assess PsA were most adept at addressing patient-reported effects on physical, emotional, and some social concepts (e.g., fatigue, depression/ sadness, relationships, and social activities) in our study. However, other social aspects of disease (family burden) and cognitive issues (mental impairment) were not identified by any of the PRO instruments used in our analysis, suggesting that either patients did not prioritize those domains during development of these PRO instruments, or that a combination of existing tools should be used to cover any gaps. These results share similarities to another qualitative focus group study, which found that of 54 concepts identified from transcribed data, 19 (35\%) were not covered by any of the 9 PRO instruments evaluated, and that some of these concepts (e.g., effect of environmental factors, attitudes toward individuals with health problems, and loss of leisure time) could potentially represent important aspects of living with psoriatic disease that were not adequately addressed by self-reported measures of function ${ }^{36}$. Ultimately, each PRO instrument has its advantages and disadvantages for use in PsA, and the use of a particular tool will depend on the targeted needs of the researcher, clinician, and/or patient.

We also determined what challenges patients were experiencing in receiving treatment with biologic therapies and found that about one-third of patients with PsA reported

Personal non-commercial use only. The Journal of Rheumatology Copyright (C) 2018. All rights reserved. 

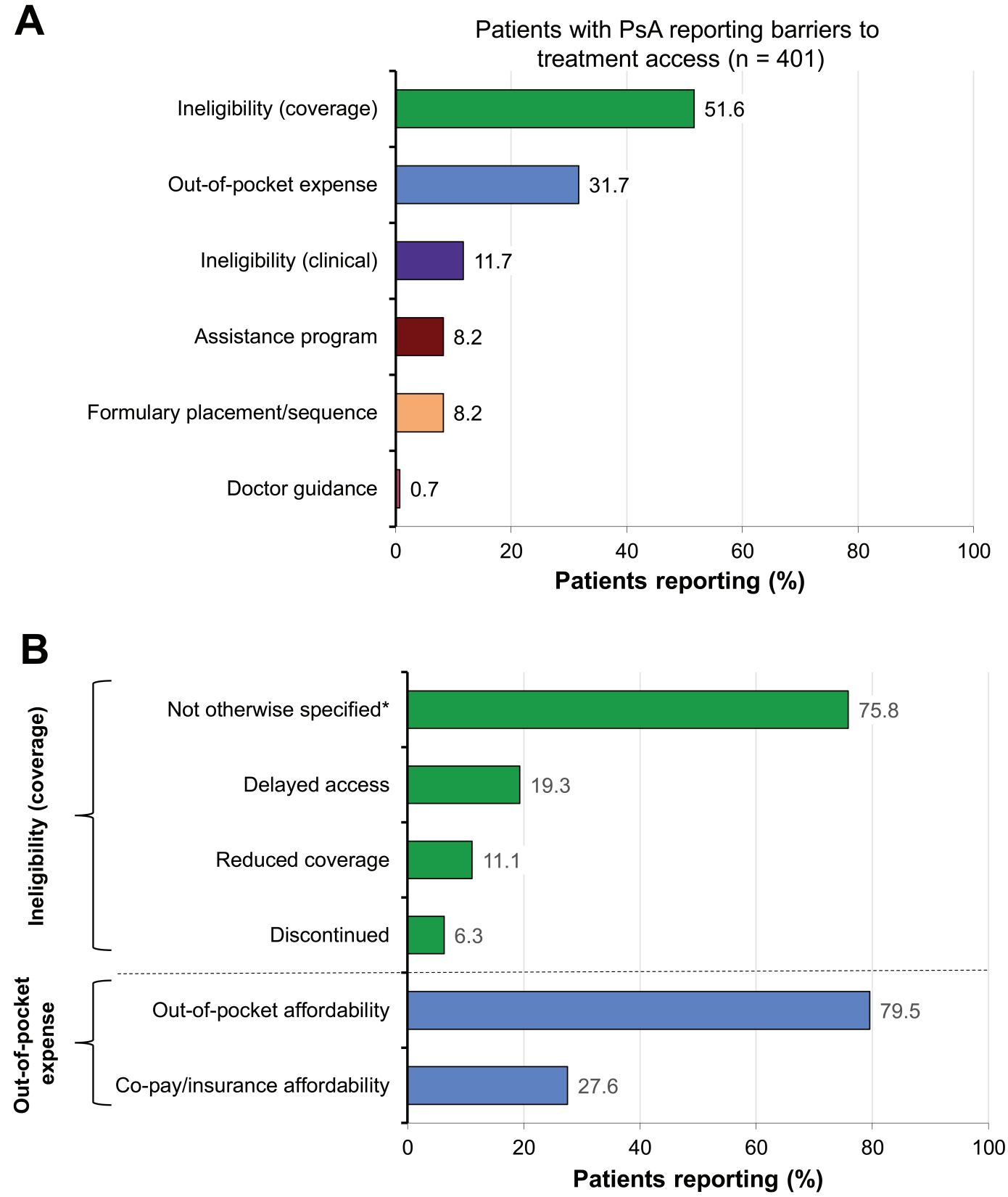

Figure 3. Barriers to treatment access identified from online patient narratives classified by (A) prespecified high-level concepts; and (B) subcategories of coverage ineligibility and out-of-pocket expenses. Data include all other reasons for coverage ineligibility (e.g., insurance provider denied treatment until confirmation of PsA diagnosis). PsA: psoriatic arthritis.

access barriers. The most commonly cited barriers to treatment were coverage ineligibility and high out-of-pocket expenses. These results were not surprising because psoriatic disease is associated with a substantial economic burden, with costs around $\$ 135$ billion annually in the United States alone ${ }^{37}$. Although data from the NPF indicate that $91 \%$ of patients with psoriatic disease have insurance coverage, out-of-pocket costs ranged anywhere from $\$ 2500$ to $\$ 8000$ in patients with psoriasis and PsA, with indirect costs accounting for $52 \%$ to $72 \%$ of total PsA costs $37,38,39,40$. Not surprisingly, increased costs are contributing to undertreatment of patients with psoriatic disease ${ }^{41}$. The Multinational Assessment of Psoriasis and Psoriatic Arthritis (MAPP) surveyed patients with psoriatic disease and found that $41 \%$ of patients with PsA were not receiving treatment consistent with established standards of care ${ }^{42}$; MAPP also found that about $20 \%$ of dermatologists and rheumatologists surveyed cited cost as a factor for not prescribing biologics to their patients with psoriasis or PsA ${ }^{43}$. Patients in our current study also cited clinical ineligibility, issues with assistance pro- 
grams, formulary placement/sequence, and guidance from their physicians as additional barriers to access to biologic treatment. Together, some of these factors may contribute to improper disease management and potentially increased health complications, consistent with findings that patients are not being treated to proper standards of care or are not satisfied with the effectiveness of their treatment ${ }^{42,44}$.

Although innovative in its design, there are some limitations that should be considered when interpreting the results. Because not all online profiles were "complete," basic demographic information was available for only a portion of patients included in our analysis, while clinical and disease characteristics of patients were largely unknown. As a result, it is difficult to compare the findings of our analysis with those of other observational studies or to generalize the findings to larger PsA populations; however, the purpose of our exploratory analysis was not to provide an accurate representation of the global PsA population, but to understand patient experiences through a new medium. Similarly, barriers to online platforms, such as socioeconomic status, age, and education level, may also limit the generalizability of these findings to larger populations. Although online platforms are largely accessible, patients making the effort to discuss their experiences online may be more heavily invested in understanding their disease than may be the overall PsA population, resulting in potential reporting bias. Despite showing the initiative to discuss their disease, some patients may not be comfortable discussing certain topics in a public online setting, suggesting that alternate data sources may be needed to evaluate those concepts more comprehensively. The narratives collected in this analysis may also be skewed toward those of newly diagnosed patients who may be looking for additional information or guidance on coping with their disease or understanding their treatments, as well as patients who are in later stages of the disease and/or have exhausted many options in management of their disease. With regard to patients reporting barriers to treatment access, we acknowledge that issues such as coverage ineligibility and out-of-pocket expenses are not relevant for all countries represented in this analysis, because of differences in reimbursement systems; however, these data do provide some insights into issues faced by patients when trying to access biologic therapies. Lastly, because all statements and experiences were based on anonymous self-reporting without any mechanism in place to verify their accuracy or confirm diagnosis of disease, some experiences may be overestimated or underestimated relative to the general PsA population. However, many narratives included language describing their diagnosis, including duration of symptoms and experiences with receiving biologic treatment, so we are confident that the proportion of patients without PsA in this sample is low.

To our knowledge, this is the first comprehensive analysis of real-world patient experiences aggregated from multiple online platforms and social media sources. These results complement results from other qualitative focus group studies and highlight the value of obtaining online self-reported experiences in patients with PsA because no single tool collects all the major concepts that patients discuss most often. Further interventions are needed to mitigate access challenges to optimal treatment options for patients with PsA.

\section{REFERENCES}

1. Michalek IM, Loring B, John SM. A systematic review of worldwide epidemiology of psoriasis. J Eur Acad Dermatol Venereol 2017;31:205-12.

2. Gladman DD. Clinical features and diagnostic considerations in psoriatic arthritis. Rheum Dis Clin North Am 2015;41:569-79.

3. Huynh D, Kavanaugh A. Psoriatic arthritis: current therapy and future approaches. Rheumatology 2015;54:20-8.

4. Gladman DD, Antoni C, Mease P, Clegg DO, Nash P. Psoriatic arthritis: epidemiology, clinical features, course, and outcome. Ann Rheum Dis 2005;64 Suppl 2:ii14-7.

5. McHugh NJ, Balachrishnan C, Jones SM. Progression of peripheral joint disease in psoriatic arthritis: a 5-yr prospective study. Rheumatology 2003;42:778-83.

6. Husted JA, Tom BD, Farewell VT, Gladman DD. Longitudinal study of the bidirectional association between pain and depressive symptoms in patients with psoriatic arthritis. Arthritis Care Res 2012;64:758-65.

7. McDonough E, Ayearst R, Eder L, Chandran V, Rosen CF, Thavaneswaran A, et al. Depression and anxiety in psoriatic disease: prevalence and associated factors. J Rheumatol 2014;41:887-96.

8. Taylor WJ, Mease PJ, Adebajo A, Nash PJ, Feletar M, Gladman DD. Effect of psoriatic arthritis according to the affected categories of the International Classification of Functioning, Disability and Health. J Rheumatol 2010;37:1885-91.

9. Ogdie A, Schwartzman S, Eder L, Maharaj AB, Zisman D, Raychaudhuri SP, et al. Comprehensive treatment of psoriatic arthritis: managing comorbidities and extraarticular manifestations. J Rheumatol 2014;41:2315-22.

10. PatientsLikeMe. Psoriatic arthritis. [Internet. Accessed January 4, 2018.] Available from: www.patientslikeme.com/conditions/ 200-psoriatic-arthritis

11. TalkPsoriasis. Psoriasis and psoriatic arthritis support group and discussion community. [Internet. Accessed January 4, 2018.] Available from: www.inspire.com/groups/talk-psoriasis

12. Living With PsA. [Internet. Accessed January 4, 2018.] Available from: www.livingwithpsoriaticarthritis.org

13. Orbai AM, Ogdie A. Patient-reported outcomes in psoriatic arthritis. Rheum Dis Clin North Am 2016;42:265-83.

14. Fries JF, Spitz P, Kraines RG, Holman HR. Measurement of patient outcome in arthritis. Arthritis Rheum 1980;23:137-45.

15. Duffy CM, Watanabe Duffy KN, Gladman DD, Brubacher BB, Buskila D, Langevitz P, et al. The utility of the arthritis impact measurement scales for patients with psoriatic arthritis. J Rheumatol 1992;19:1727-32.

16. Chandran V, Bhella S, Schentag C, Gladman DD. Functional assessment of chronic illness therapy-fatigue scale is valid in patients with psoriatic arthritis. Ann Rheum Dis 2007;66:936-9.

17. Husted J, Gladman DD, Farewell VT, Long JA. Validation of the revised and expanded version of the Arthritis Impact Measurement Scales for patients with psoriatic arthritis. J Rheumatol 1996;23:1015-9.

18. Husted JA, Gladman DD, Farewell VT, Long JA, Cook RJ. Validating the SF-36 health survey questionnaire in patients with psoriatic arthritis. J Rheumatol 1997;24:511-7.

Personal non-commercial use only. The Journal of Rheumatology Copyright (c) 2018. All rights reserved. 
19. McKenna SP, Doward LC, Whalley D, Tennant A, Emery P, Veale DJ. Development of the PsAQoL: a quality of life instrument specific to psoriatic arthritis. Ann Rheum Dis 2004;63:162-9.

20. Bushnell DM, Martin ML, McCarrier K, Gordon K, Chiou CF, Huang X, et al. Validation of the Psoriasis Symptom Inventory (PSI), a patient-reported outcome measure to assess psoriasis symptom severity. J Dermatolog Treat 2013;24:356-60.

21. Gossec L, de Wit M, Kiltz U, Braun J, Kalyoncu U, Scrivo R, et al. A patient-derived and patient-reported outcome measure for assessing psoriatic arthritis: elaboration and preliminary validation of the Psoriatic Arthritis Impact of Disease (PsAID) questionnaire, a 13-country EULAR initiative. Ann Rheum Dis 2014;73:1012-9.

22. Tillett W, Adebajo A, Brooke M, Campbell W, Coates LC, FitzGerald O, et al. Patient involvement in outcome measures for psoriatic arthritis. Curr Rheumatol Rep 2014;16:418.

23. Palominos PE, Gaujoux-Viala C, Fautrel B, Dougados M, Gossec L. Clinical outcomes in psoriatic arthritis: A systematic literature review. Arthritis Care Res 2012;64:397-406.

24. Gudu T, Kiltz U, de Wit M, Kvien T, Gossec L. Mapping the effect of psoriatic arthritis using the International Classification of Functioning, Disability and Health. J Rheumatol 2017;44:193-200.

25. Orbai AM, de Wit M, Mease PJ, Callis Duffin K, Elmamoun M, Tillet W, et al. Updating the psoriatic arthritis (PsA) core domain set: a report from the PsA Workshop at OMERACT 2016. J Rheumatol 2017;44:1522-8.

26. Ware JE Jr, Sherbourne CD. The MOS 36-item short-form health survey (SF-36). I. Conceptual framework and item selection. Med Care 1992;30:473-83.

27. McHorney CA, Ware JE Jr, Raczek AE. The MOS 36-Item Short-Form Health Survey (SF-36): II. Psychometric and clinical tests of validity in measuring physical and mental health constructs. Med Care 1993;31:247-63.

28. Leung YY, Zhu TY, Tam LS, Kun EW, Li EK. Minimal important difference and responsiveness to change of the SF-36 in patients with psoriatic arthritis receiving tumor necrosis factor-alpha blockers. J Rheumatol 2011;38:2077-9.

29. Gladman D, Fleischmann R, Coteur G, Woltering F, Mease PJ. Effect of certolizumab pegol on multiple facets of psoriatic arthritis as reported by patients: 24 -week patient-reported outcome results of a phase III, multicenter study. Arthritis Care Res 2014;66:1085-92.

30. Kavanaugh A, McInnes IB, Krueger GG, Gladman D, Beutler A, Gathany T, et al. Patient-reported outcomes and the association with clinical response in patients with active psoriatic arthritis treated with golimumab: findings through 2 years of a phase III, multicenter, randomized, double-blind, placebo-controlled trial. Arthritis Care Res 2013;65:1666-73.

31. Rahman P, Puig L, Gottlieb AB, Kavanaugh A, McInnes IB, Ritchlin $\mathrm{C}$, et al. Ustekinumab treatment and improvement of physical function and health-related quality of life in patients with psoriatic arthritis. Arthritis Care Res 2016;68:1812-22.

32. Mease P, Genovese MC, Gladstein G, Kivitz AJ, Ritchlin C, Tak PP, et al. Abatacept in the treatment of patients with psoriatic arthritis: results of a six-month, multicenter, randomized, double-blind, placebo-controlled, phase II trial. Arthritis Rheum 2011;63:939-48.
33. Strand V, Sharp V, Koenig AS, Park G, Shi Y, Wang B, et al. Comparison of health-related quality of life in rheumatoid arthritis, psoriatic arthritis and psoriasis and effects of etanercept treatment. Ann Rheum Dis 2012;71:1143-50.

34. Strand V, Schett G, Hu C, Stevens RM. Patient-reported healthrelated quality of life with apremilast for psoriatic arthritis: a phase II, randomized, controlled study. J Rheumatol 2013;40:1158-65.

35. Orbai AM, de Wit M, Mease P, Shea JA, Gossec L, Leung YY, et al. International patient and physician consensus on a psoriatic arthritis core outcome set for clinical trials. Ann Rheum Dis 2017;76:673-80.

36. Stamm TA, Nell V, Mathis M, Coenen M, Aletaha D, Cieza A, et al. Concepts important to patients with psoriatic arthritis are not adequately covered by standard measures of functioning. Arthritis Rheum 2007;57:487-94.

37. Brezinski EA, Dhillon JS, Armstrong AW. Economic burden of psoriasis in the United States: a systematic review. JAMA Dermatol 2015;151:651-8

38. Bhutani T, Wong JW, Bebo BF, Armstrong AW. Access to health care in patients with psoriasis and psoriatic arthritis: data from National Psoriasis Foundation survey panels. JAMA Dermatol 2013;149:717-21.

39. Lee S, Mendelsohn A, Sarnes E. The burden of psoriatic arthritis: a literature review from a global health systems perspective. P T 2010;35:680-9.

40. Williams EM, Walker RJ, Faith T, Egede LE. The impact of arthritis and joint pain on individual healthcare expenditures: findings from the Medical Expenditure Panel Survey (MEPS), 2011. Arthritis Res Ther 2017;19:38

41. Armstrong AW, Robertson AD, Wu J, Schupp C, Lebwohl MG. Undertreatment, treatment trends, and treatment dissatisfaction among patients with psoriasis and psoriatic arthritis in the United States: findings from the National Psoriasis Foundation surveys, 2003-2011. JAMA Dermatol 2013;149:1180-5.

42. Lebwohl MG, Bachelez H, Barker J, Girolomoni G, Kavanaugh A, Langley RG, et al. Patient perspectives in the management of psoriasis: results from the population-based Multinational Assessment of Psoriasis and Psoriatic Arthritis Survey. J Am Acad Dermatol 2014;70:871-81.

43. van de Kerkhof PC, Reich K, Kavanaugh A, Bachelez H, Barker J, Girolomoni G, et al. Physician perspectives in the management of psoriasis and psoriatic arthritis: results from the population-based Multinational Assessment of Psoriasis and Psoriatic Arthritis survey. J Eur Acad Dermatol Venereol 2015;29:2002-10.

44. Lebwohl MG, Kavanaugh A, Armstrong AW, Van Voorhees AS. US perspectives in the management of psoriasis and psoriatic arthritis: patient and physician results from the population-based Multinational Assessment of Psoriasis and Psoriatic Arthritis (MAPP) survey. Am J Clin Dermatol 2016;17:87-97. 
APPENDIX 1. List of online sources used in analyses of functional impairment and treatment access.

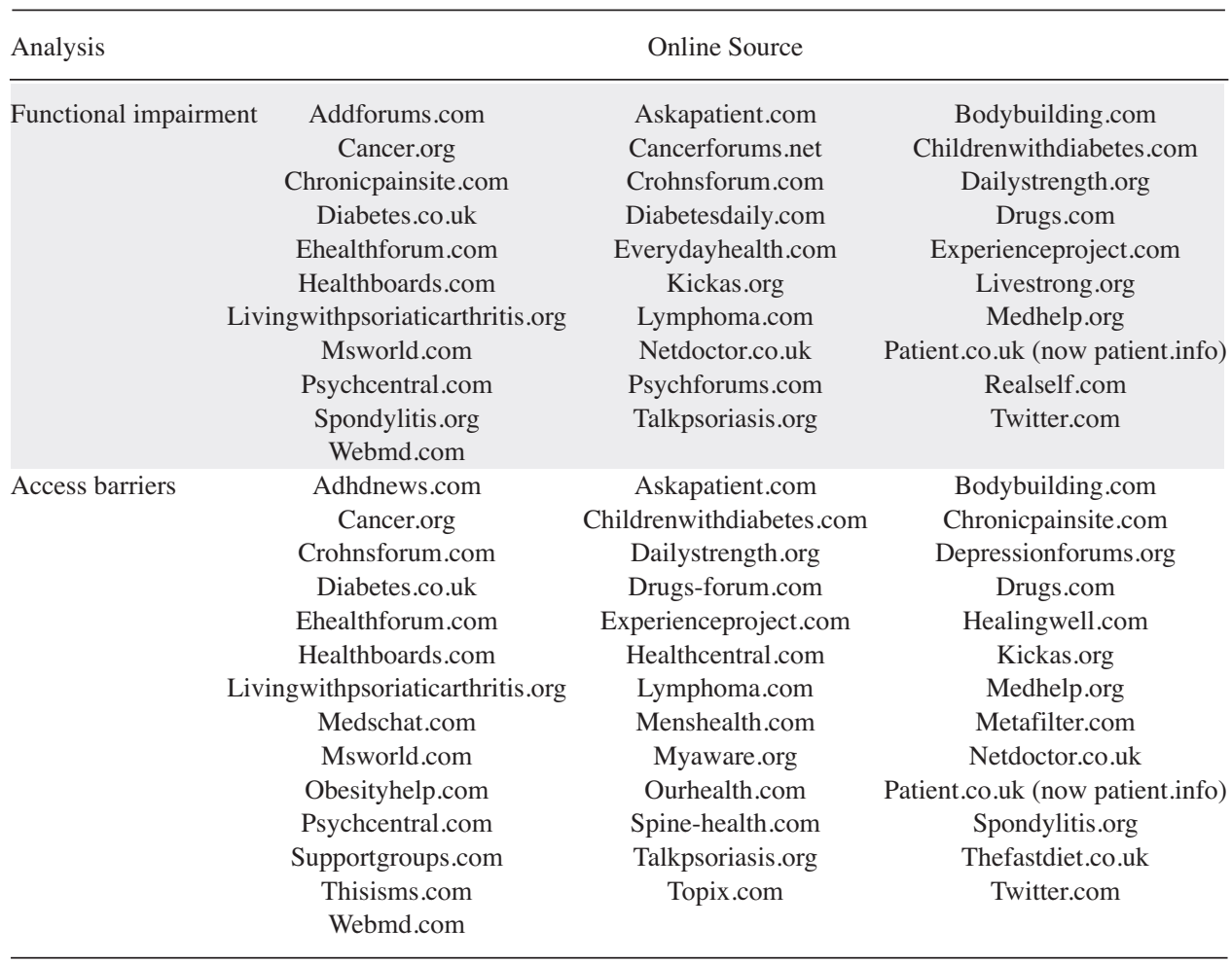

